ORIGINAL RESEARCH ARTICLE

\title{
Partner Support for Family Planning and Modern Contraceptive Use in Luanda, Angola
}

\author{
Ndola Prata $^{1 *}$, Suzanne Bell ${ }^{1}$, Ashley Fraser ${ }^{1}$, Adelaide Carvalho ${ }^{2}$, Isilda Neves ${ }^{2}$ and Benjamin \\ Nieto-Andrade ${ }^{3}$
}

Bixby Center for Population, Health and Sustainability, School of Public Health, University of California, Berkeley, 229 University Hall, UC-Berkeley, Berkeley, CA 94720-7360, USA ${ }^{1}$; National Directorate of Public Health, Ministry of Health, Angola ${ }^{2}$; Population Services International (PSI), Angola ${ }^{3}$

*For Correspondence: Email: ndola@berkeley.edu, Phone: (1) 510-643-4284

\begin{abstract}
Husband's/partner's support for family planning may influence a women's modern contraceptive use. Socio-demographic factors, couple communication about family planning, and fertility preferences are known to play a role in contraceptive use. We conducted logistic regression analysis to investigate the relationship between perceived husband's/partner's approval and husband's/partner's encouragement of modern contraceptive use, adjusting for socio-demographic factors and recent couple communication about family planning. We also examined mediating roles potentially played by perceived contraceptive accessibility and contraceptive self-efficacy (using index created by principal component analysis). Perceived husband's/partner's approval was associated with triple the odds of women's modern contraceptive use and remained significantly associated with 1.6 times the odds, after controlling for contraceptive accessibility and contraceptive self-efficacy. Husband's/partner's encouragement, while initially significantly associated with contraceptive use, became non-significant after adjustments for socio-demographic factors and couple communication. Perceived husband's/partner's approval, separate from a woman's sense of self-efficacy and perceived accessibility of contraceptives, appears strongly and positively associated with current modern contraceptive use. Increased couple communication may help women identify their husband's/partner's approval. Difference between the meaning of approval and encouragement should be explored. Interventions involving information education and communication campaigns geared to men and promoting male involvement in family planning could increase contraceptive prevalence. (Afr J Reprod Health 2017; 21[2]: 35-48).
\end{abstract}

Key words: Contraception, male involvement, approval, encouragement, sub-Saharan Africa

\section{Résumé}

Le soutien du mari ou du partenaire pour la planification familiale peut influencer l'utilisation des contraceptifs modernes chez les femmes. Les facteurs sociodémographiques, la communication en couple sur la planification familiale et les préférences en matière de fécondité jouent un rôle dans l'utilisation des contraceptifs. Nous avons procédé à une analyse de régression logistique pour étudier la relation entre l'approbation perçue du mari /du partenaire et l'encouragement du mari / du partenaire à l'utilisation des contraceptifs modernes, en adaptant les facteurs sociodémographiques et la communication récente sur la planification familiale. Nous avons également examiné les rôles médiateurs potentiellement joués par l'accessibilité des contraceptifs perçue et l'auto-efficacité des contraceptifs (en utilisant l'indice créé par l'analyse des composantes principales). L'approbation perçue du mari / du partenaire était associée au triple des probabilités d'utilisation des contraceptifs modernes des femmes et est restée significativement associée à 1,6 fois la probabilité, après avoir contrôlé l'accessibilité des contraceptifs et l'auto-efficacité des contraceptifs. Les encouragements du conjoint et du partenaire, tout en étant initialement associés à l'utilisation des contraceptifs, sont devenus non significatifs après des ajustements pour les facteurs sociodémographiques et la communication en couple. L'approbation perçue du mari / du partenaire, séparée du sentiment d'auto-efficacité d'une femme et de l'accessibilité perçue des contraceptifs, apparaît fortement et positivement associée à l'utilisation actuelle des contraceptifs modernes. Une communication accrue en couple peut aider les femmes à identifier l'approbation de leur mari /de leur partenaire. La différence entre la signification de l'approbation et l'encouragement devrait être explorée. Les interventions impliquant des campagnes d'information et de communication axées sur les hommes et la promotion de la participation des hommes à la planification familiale pourraient accroître la prévalence des contraceptifs. (Afr J Reprod Health 2017; 21[2]: 35-48).

Mots clés: planification familiale, soutien du partenaire masculin, Angola 


\section{Introduction}

Several studies have examined how wife's and husband's fertility intentions predict future fertility and contraceptive use and results indicate that incorporating both spouses' attitudes improves predictability compared to including just one spouse's attitudes ${ }^{1-5}$. Results vary regarding which spouse's fertility intentions has greater predictive value. Incorporating husbands' fertility intentions in models may improve predictability of subsequent fertility ${ }^{6}$. Spousal communication about fertility and family planning in Africa is notoriously low and greater communication may increase the accuracy of a spouse's perception of the other spouse's approval of family planning depending on the setting and prevailing norms, among other factors ${ }^{7,8}$. Although wives' proxy report of husbands' approval of family planning has low validity, her perception of his approval may still provide insight into her contraceptive choices $^{6,7}$. Cultural context may be especially important. For example, a study in India found couple data was needed to accurately assess family planning attitudes and intentions 9 . However, a previous study in Kenya found wives' incorrect perception of husbands' attitudes to be a significant predictor of behavior (i.e. contraceptive use) $)^{7}$. Among post-abortion care clients in Zanzibar, a woman's perceived husband's/partner's support for contraceptive use trumped all other factors in determining her family planning intentions ${ }^{10}$. As study of the effect of spousal agreement on fertility and spousal communication on contraceptive use in Jimma zone, Ethiopia found both factors played important roles in uptake ${ }^{11}$.

Evidence suggests husband's/partner's support for family planning influences a woman's modern contraceptive use ${ }^{12-14}$. A strategic mapping exercise of qualitative factors associated with low utilization of family planning services in Angola in the immediate post-conflict period cited male opposition to family planning and limited female decision-making power as important barriers to contraceptive use ${ }^{15}$. Mixed methods research using national data and qualitative interviews with health providers identified barriers to contraceptive use, such as cultural beliefs and power imbalances, among internally displaced Angolan women ${ }^{16}$. However, we have an incomplete understanding of how attitudes and perceptions might interact with each other and other variables. In particular, to our knowledge, there is no research investigating the influence of husband's/partner's approval and gender dynamics on modern contraceptive use in Angola.

The purpose of this paper is to assess the relationship between (1) husband's/partner's approval, and (2) husband's/partner's encouragement of the use of modern contraceptives use based on women's perceptions. We selected both independent variables for this analysis after noting a lack of alignment between categories of these seemingly similar forms of partner support. We also isolate any direct effects of perceived approval or encouragement by identifying and controlling any mediating role potentially played by i) women's self-efficacy and ii) perceived contraceptive accessibility.

Situated in southern Africa, Angola is home to a population of 24.3 million $^{17}$. After decades of civil war and unrest, thousands of Angolans are poor and displaced, lacking access to some of the most basic health care services. Angola's capital and largest city, Luanda, where $27 \%$ of the population resides ${ }^{17}$, is characterized by high fertility (TFR=6.9 children per woman) and low contraceptive prevalence rate $(17.7 \%)$. The unmet need for family planning is estimated to be $44 \%$, $19 \%$ of which is for limiting childbearing ${ }^{18}$. In Angola, significant barriers exist, including widespread and extreme poverty and lack of knowledge and understanding related to family planning and contraception. For example, only $60 \%$ of women know of a modern method of contraception in Luanda province ${ }^{18}$. A KAP survey conducted in Luanda province in 2009 reported that the reason most commonly cited by women for not using contraceptives was lack of knowledge $(33 \%)^{19}$.

\section{Methods}

Researchers from the University of California, Berkeley Bixby Center for Population, Health and 
Sustainability developed a survey instrument modeled on the Women's Questionnaire of the Demographic and Health Surveys (DHS) and Angola's Malaria Indicator Survey and also included standardized Population Services International (PSI) questions on opportunity, ability, and motivation. The survey questions capture women's knowledge, attitudes, and practices as well as their opportunities, ability, and motivation related to childbearing and family planning. The survey also collected information regarding women's experiences with reproductive health services and their preferences related to the delivery of family planning services. All items and response options in the survey instrument were initially developed in English and later translated into Portuguese by the research team, with feedback from PSI Angola. Once finalized, the survey instrument was pilot tested among women of reproductive age in Luanda, Angola. Feedback from this phase was incorporated and the final pilot-tested version was then back- translated into English to ensure accuracy.

Using a multi-stage random sampling design, researchers captured a representative sample of women of reproductive age from all municipalities in Luanda Province where the capital city of Luanda is located. The municipality sample was proportional to population size of each municipality. All women provided consent before taking part in the interview. The survey had the targeted goal of providing a representative family planning needs assessment before the development and implementation of public and private sector family planning programming and an information, education, and communication (IEC) campaign with PSI Angola. A more detailed description of the data, methodology, and findings has been published in a 2012 Luanda Community Survey Report. $^{20}$ To our knowledge, the only other recently gathered socio-demographic data were collected by the Angolan National Institute of Statistics (INE) for the Inquérito Integrado Sobre o Bem-Estar da População or Integrated Survey on the Welfare of Population (IBEP) living standards measurement survey in 2009, which contained
UNICEF multiple indicators cluster survey (MICS) modules. ${ }^{21}$ Ethical approval for this study was provided by the University of California, Berkeley Center for Protection of Human Subjects (CPHS \# 2011-08-3521). Approval was also provided by the Ethical Committee at the Instituto de Saude Publica in Luanda, Angola.

In this analysis, we assess whether perceived husband's/partner's approval and encouragement of the use of contraception is associated with current modern contraceptive use. Our hypothesis is that husband's/partner's approval of contraceptive use (as perceived by the woman being surveyed) is independently associated with current modern contraceptive use. We also hypothesize that this relationship is mediated by contraceptive self-efficacy and perceived contraceptive accessibility. Controlling for these mediators would potentially isolate the direct effect, if any, of perceived husband's/partner's approval of contraceptive use, after controlling for other socio-demographic factors and husband's/partner's communication (Fig 1). We also hypothesize that this relationship would be similar for husband's/partner's encouragement of the woman to use contraception. We theorized that husband's/partner's approval as perceived by the respondent and husband's/partner's encouragement could serve as proxies for complex gender dynamics and husband's/partner's support that characterize the context in which women make family planning decisions and shed light on potential avenues for interventions, particularly pointing to salient messages for information, education, and communication (IEC) campaigns. (Figure 1)

Our dependent variable, current use of modern methods of family planning, was dichotomous yes vs. no, with "no" as reference group, which encompassed both non-users of any form of modern contraception and users of traditional methods. Given the small number of users of traditional $(\mathrm{n}=35,2.6 \%)$, traditional method users were combined with those using no modern method at all. Our first independent variable of interest, "Approval of family 


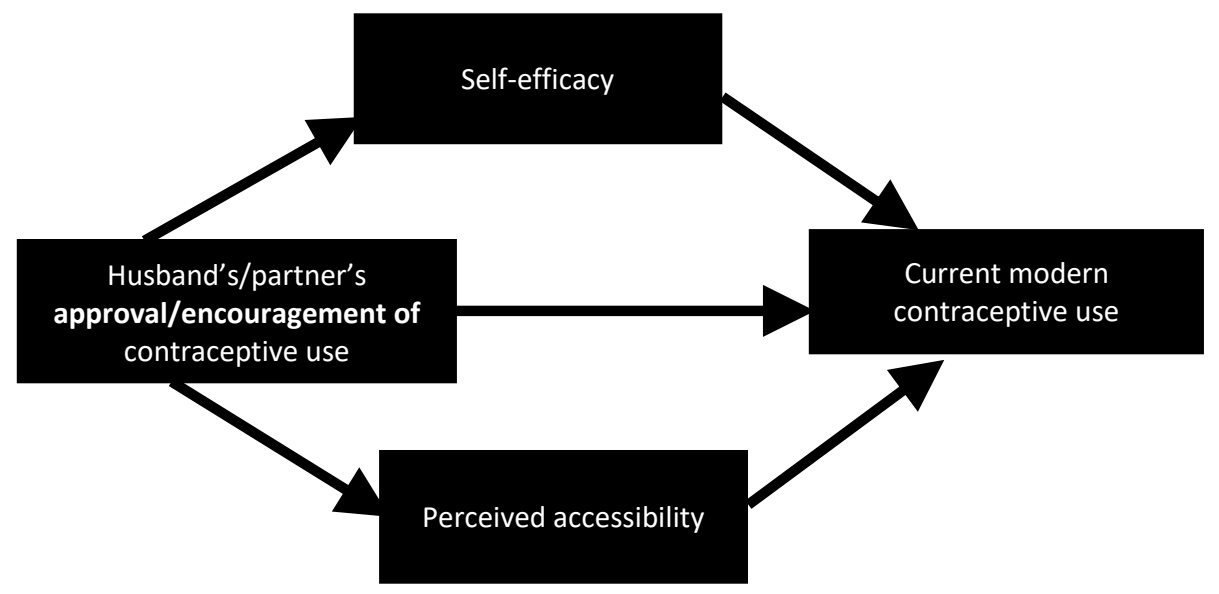

Figure 1: Hypothesis

planning," was captured by the question: Do you think your husband/partner/boyfriend approves of couples using family planning? Responses were categorized dichotomously (a) yes vs. (b) no or don't know, with no/don't know as reference group. Our second independent variable of interest, "Encouragement of respondent to use contraception", was taken from a variable measured on a Likert scale (My husband encourages me to use family planning), collapsed into three categories: strongly agree/agree, indifferent, and disagree/strongly disagree. The latter acted as the reference group.

Socio-demographic variables included age, marital status, education, and wealth quintile derived from a principal components analysis (PCA) of household assets, including building materials and household amenities, following the methodology used by Demographic and Health Surveys (DHS). Recent couple communication was assessed by the number of times surveyed women had discussed family planning with her husband/partner in the last year (none, once or twice, more often). The contraceptive self-efficacy index was developed using PCA of variables included in the survey which measure selfefficacy, including: capability of using contraceptives; ability to use methods correctly and consistently space births; communicate about preventing pregnancy; negotiate contraceptive use; and use contraception in the face of husband/partner opposition (see Table 4). Perceived accessibility of contraception is dichotomously coded, yes/no, in response to the question:

\section{Are contraceptives accessible to you?}

We conducted bivariate analysis on the two independent variables. Multivariate analyses were conducted separately on each independent variable of interest. Models were built in two stages: 1) Model 1 controls for socio-demographic characteristics and recent couple communication about family planning; 2) Model 2 add the potential mediators to Model 1 i) a women's sense of contraceptive self-efficacy and ii) perceived accessibility of contraception. Statistical significance was established at $\mathrm{p}-<0.05$.

\section{Results}

Our data are derived from a larger study sample of 1,825 Angolan women of reproductive age living in Luanda. This analytical sample was restricted to non-pregnant, non-sterilized, fecund and sexually active women of reproductive age who completed the survey and were married/had boyfriend/had husband/had partner (husband/partner) $(\mathrm{n}=1,227)$. As shown in Table 1, slightly more than half of the sample was currently using modern methods of 
Table 1: Background Characteristics among Women of Reproductive Age by Current Modern Method Use

\begin{tabular}{|c|c|c|c|c|c|c|}
\hline \multirow{3}{*}{ Variable } & \multicolumn{6}{|c|}{ Current Use of Modern Methods } \\
\hline & \multicolumn{2}{|c|}{ Users } & \multicolumn{2}{|c|}{ Unadjusted Odds Ratio } & & \multirow{2}{*}{$\begin{array}{l}\text { Total }^{* *} \\
\mathbf{N}=1227\end{array}$} \\
\hline & $\%$ & $\mathrm{~N}=745$ & OR & $95 \% \mathrm{CI}$ & & \\
\hline All & 60.7 & 745 & & & & 1227 \\
\hline \multicolumn{7}{|l|}{ Age* } \\
\hline $15-19$ & 44.4 & 149 & - & Reference & & 336 \\
\hline $20-24$ & 68.2 & 214 & 2.69 & $1.94-3.70$ & $*$ & 314 \\
\hline $25+$ & 66.5 & 381 & 2.49 & $1.89-3.28$ & $*$ & 573 \\
\hline \multicolumn{7}{|l|}{ Current marital status* } \\
\hline Not married/cohabiting & 57.2 & 494 & - & Reference & & 863 \\
\hline Married/cohabiting & 69.0 & 251 & 1.66 & $1.28-2.15$ & $*$ & 364 \\
\hline \multicolumn{7}{|l|}{ Education* } \\
\hline No education/grades 1-6 & 47.0 & 63 & - & Reference & & 134 \\
\hline Grades 7-9 & 57.3 & 216 & 1.51 & $1.02-2.25$ & $*$ & 377 \\
\hline Grades $10-13 /$ Univ. or more & 65.1 & 466 & 2.10 & $1.45-3.05$ & $*$ & 716 \\
\hline \multicolumn{7}{|l|}{ Wealth quintile* } \\
\hline 1 st (poorest) & 53.8 & 127 & - & Reference & & 236 \\
\hline $2^{\text {nd }}$ & 54.7 & 133 & 1.04 & $0.72-1.47$ & & 243 \\
\hline $3^{\text {rd }}$ & 63.0 & 155 & 1.46 & $1.02-2.10$ & $*$ & 246 \\
\hline $4^{\text {th }}$ & 62.0 & 152 & 1.40 & $0.98-2.02$ & & 245 \\
\hline 5th (wealthiest) & 68.5 & 172 & 1.87 & $1.29-2.70$ & $*$ & 251 \\
\hline \multicolumn{7}{|c|}{ Total number of children ever born* } \\
\hline 0 & 53.3 & 329 & - & Reference & & 617 \\
\hline $1-2$ & 64.2 & 203 & 1.57 & $1.19-2.08$ & $*$ & 316 \\
\hline $3-4$ & 75.0 & 132 & 2.63 & $1.80-3.83$ & $*$ & 176 \\
\hline $5+$ & 68.6 & 81 & 1.92 & $1.26-2.92$ & $*$ & 118 \\
\hline Number & & have & talked & to & husband/ & \\
\hline \multicolumn{7}{|c|}{ partner about family planning in the past year* } \\
\hline Never & 43.4 & 212 & - & Reference & & 489 \\
\hline Once or twice & 70.9 & 248 & 3.18 & $2.37-4.25$ & $*$ & 350 \\
\hline More often & 73.5 & 285 & 3.62 & $2.71-4.82$ & $*$ & 388 \\
\hline \multicolumn{7}{|l|}{ Perceives contraception as accessible* } \\
\hline No & 36.6 & 135 & - & Reference & & 369 \\
\hline Yes & 71.1 & 610 & 4.26 & $3.29-5.19$ & $*$ & 858 \\
\hline \multicolumn{7}{|l|}{ PCA Self Efficacy Scores* } \\
\hline Scores $0-<3$ & 34.6 & 47 & - & Reference & & 136 \\
\hline Scores $3-<4$ & 61.4 & 516 & 3.01 & $2.06-4.39$ & $*$ & 841 \\
\hline Scores 4-5 & 72.8 & 182 & 5.07 & $3.23-7.95$ & $*$ & 250 \\
\hline
\end{tabular}

* Chi $i^{2}$ or OR $p$-value $\leq 0.05$

** Row \% add to $100 \%$

contraception (61\%) while the rest (39\%) was not. As expected, sample characteristics of current users of modern methods of family planning were significantly different from those of current nonusers of modern methods $(\mathrm{p}=0.000)$. Higher proportions of older women (67\%-68\%), currently married/cohabitating women (69\%), and more educated women $(65 \%)$, and women in the highest wealth quintile rank than lowest (69\%) were current users of modern methods. The inverse was true for non-users. Higher proportions of women who had given birth three to four times $(75 \%)$ were currently using contraception compared to women who had never given birth or had done so less than three or more than four times. Among users, two fifths (43\%) of the sample had not spoken with their husbands/partners about family planning in the last year. Compared to women who 
did were modern users $(71 \%)$. The proportion of women who had the highest scores on the selfefficacy scale was greater among current modern method users $(73 \%)$ than among their counterparts with lower self-efficacy scores. The variables, which were measured 5-point Likert scale, and included in the principal component analysis used to create the self-efficacy measures, and their mean scores, are presented by contraceptive use in Table 4.

As indicated in Table 2, both forms of husband's/partner's support differed significantly according to modern method use, as did reported couple agreement on the desired number of children $(\mathrm{p} \leq 0.05)$. Half of women included in our sample (55\%) reported their husbands approve of couples using family planning. Few of the husbands disapproved (8\%), but around a third of women $(36 \%)$ did not know their husbands opinion on the topic (not shown). Among women who believed their husbands approve of couples using family planning, most were current modern method users $(72 \%)$. Notably, the majority of those who believed their husbands did not approve were also current modern contraceptive users $(63 \%)$. A higher proportion of the women who agreed they were encouraged to use contraception by their husbands/partners $(66 \%)$ were modern method users than those who were indifferent or whose husbands did not encouraged (54-55\%).

The distribution of husband's/partner's approval and encouragement varied significantly so that approval did not coincide with encouragement. For example, of the $55 \%$ of women who perceived their husband's/partner's approved of couples using family planning, only $65 \%$ agreed/completely agreed their husband's/partner's encouraged them to use family planning (data not shown). Most of the women who did not know their husband's opinion on couples using modern methods were non-users $(57 \%)$. Overall, half of the sample reported their husbands/partners encouraged them to use contraception (54\%), most of the remaining women neither agreed nor disagreed $(26 \%)$ while one fifth did not report husband's/partner's encouragement (20\%) (not shown). Whereas, among the $45 \%$ of women who reported their husbands/partners disapproved or did not know their partner's opinion, 74\% agreed/completely agreed that their husbands/partners encouraged them to use contraception (not shown).

Around half of the women in the sample were unsure of whether their husband/partner wanted the same number of children as they did (49\%) (not shown). A quarter $(27 \%)$ concurred with their husband/partner on their ideal family size, and the remainder (24\%) reported discordant desires, more often due to partners wanting more children (not shown). The majority of women who desired the same number of children as their husband/partner currently used modern contraception (67\%). A proportion of women whose husband/partner wanted more children than they did $(73 \%)$ currently used modern methods and a smaller majority of those whose partners wanted fewer children (57\%) did so as well. Less than half of the women who were unsure of their partner's desired family size were current nonusers (45\%) (Data not shown).

As shown in Table 1, bivariate analysis also found that all sample characteristics and mediating variables were significantly associated with current use of modern contraception. For example, compared with the youngest women, the odds of current modern method use were almost triple for older age groups ((20-24 years olds: unadjusted $\mathrm{OR}=2.7,95 \% \mathrm{CI} 1.9-3.7)$ and (25+ years olds: unadjusted $\mathrm{OR}=2.5,95 \%$ CI 1.9-3.3)). Married women were almost twice as likely (unadjusted $\mathrm{OR}=1.7,95 \% \mathrm{CI} 1.3-2.2$ ) as women who were not married to currently use modern methods. Compared to the least educated and lowest wealth quintile women, the more educated ((Grades 7-9: unadjusted OR=1.5, 95\% CI 1.0-2.3) and Grades 10+: unadjusted OR=2.1, 95\% CI 1.5$3.1))$ and $3^{\text {rd }}$ and $5^{\text {th }}$ quintile women $\left(\left(3^{\text {rd }}\right.\right.$ quintile: unadjusted $\mathrm{OR}=1.5,95 \% \mathrm{CI} 1.0-2.1)$ and $\left(5^{\text {th }}\right.$ quintile: unadjusted $\mathrm{OR}=1.9$, 95\% CI 1.3-2.7)) were significantly more likely to use modern methods. Compared to women with no children, women with more than more children were more likely to use contraception (unadjusted $\mathrm{OR}=1.6$ 2.6, 95\% CI 1.2-3.8). Couple communication more 
Table 2: Family Planning Beliefs and Communication about Family Planning by Current Modern Method Use

\begin{tabular}{|c|c|c|c|c|c|c|}
\hline \multirow{3}{*}{ Variable } & \multicolumn{6}{|c|}{ Current Use of Modern Methods } \\
\hline & \multicolumn{2}{|l|}{ Users } & \multicolumn{3}{|c|}{ Unadjusted Odds Ratio } & \multirow{2}{*}{$\begin{array}{l}\text { Total } * * \\
\mathbf{N}=1227\end{array}$} \\
\hline & $\%$ & $\mathrm{~N}=\mathbf{7 4 5}$ & $\mathbf{O R}$ & $95 \% \mathrm{CI}$ & & \\
\hline \multicolumn{7}{|c|}{ Husband's/partner's opinion of couples using family planning to avoid pregnancy* } \\
\hline Disapproves/Don't know & & & - & Reference & & \\
\hline Disapproves & 63.5 & 66 & & & & 104 \\
\hline Don't know & 43.1 & 193 & & & & 448 \\
\hline \multicolumn{7}{|l|}{ Appro } \\
\hline ves & 72.0 & 486 & 2.91 & $2.30-3.69$ & $*$ & 675 \\
\hline \multicolumn{7}{|l|}{ My husband encourages me to use family planning* } \\
\hline Completely Disagree/Disagree & 54.6 & 137 & - & Reference & & 251 \\
\hline Indifferent (neither agreed nor disagreed) & 53.7 & 169 & 0.96 & $0.69-1.34$ & & 315 \\
\hline Agree/Completely Agree & 66.4 & 439 & 1.65 & $1.22-2.21$ & $*$ & 661 \\
\hline \multicolumn{7}{|c|}{ Husband/partner wants/wanted same number of children as respondent* } \\
\hline Same number & $67.0^{1}$ & 221 & - & Reference & & 330 \\
\hline More children & 72.6 & 119 & 1.30 & $0.86-1.97$ & & 164 \\
\hline Fewer children & 57.4 & 74 & 0.66 & $0.44-1.01$ & & 129 \\
\hline Unsure & 54.8 & 331 & 0.60 & $0.45-0.79$ & $*$ & 604 \\
\hline
\end{tabular}

than tripled the odds of current modern use (unadjusted $\mathrm{OR}=3.2-3.6$, 95\% CI 2.4-4.8). The odds of current modern method use were significantly greater for each potential meditator, perceived accessibility of contraception (unadjusted $\mathrm{OR}=4.3$, 95\% CI 3.3-5.2) and selfefficacy scores of three or above (unadjusted $\mathrm{OR}=3.0-5.1,95 \%$ CI 2.1-8.0).

Table 2 shows, in unadjusted analysis, both forms of husband's/partner's support were significantly associated with current modern method use. Women who perceive their partners as approving of couples using family planning were nearly three times more likely to currently use modern methods than those whose partners did not approve (unadjusted $\mathrm{OR}=2.9,95 \%$ CI 2.3-3.7). Compared to women who disagreed/completely disagreed that their partner encourages them to use contraception, women who were indifferent were not significantly more likely to currently use modern methods, whereas women who completely agreed/agreed were significantly more likely to do so (unadjusted $\mathrm{OR}=1.7,95 \%$ CI 1.2-2.2). Women who are not sure if they are in agreement with their husband on the number of children to have were significantly less likely to currently use modern methods (unadjusted $\mathrm{OR}=0.60,95 \% \mathrm{CI}$ 0.5-0.8).
As shown in Table 3 in Model 1, we found the association between partner's approval of couples using family planning and modern method use dropped from 2.9 (unadjusted) to 1.9 but remained significant (95\% CI 1.4-2.4), after controlling for sociodemographic variables and recent spousal communication. Most control variables, such as age, education, the number of children ever born, and recent couple communication, were significantly associated with use of modern methods, after adjustment. However, marital status and wealth quintile, significantly associated with modern method use in bivariate analysis, lost their significance in the adjusted model. We tested replacing couple communication with couple agreement on the desired family size in Model 1 but reported concordance on ideal family size was not significant so it was dropped from the analysis.

Model 2 shows, after controlling for potential meditating variables, contraceptive accessibility and contraceptive self-efficacy, the association between perceived husband's/partner's approval and modern method use dropped further to 1.6 times the odds but retained its significance (95\% CI 1.2-2.1). In the fully adjusted model, women aged 20-24 years old were twice as likely to use modern methods as their younger counterparts $(\mathrm{AOR}=1.9,95 \% \mathrm{CI} 1.3-2.8)$ but 
Table 3: Logistic Regression: Odds Ratio Between (A) Husband's/Partner's Approval \& (B) Husband's/Partner's Encouragement of Family Planning and Current Modern Contraceptive Use

\begin{tabular}{|c|c|c|c|c|c|c|c|c|c|c|c|c|}
\hline \multirow[b]{3}{*}{ Variable } & \multicolumn{6}{|c|}{ Husband approves of couples using family planning (A) } & \multicolumn{6}{|c|}{ Husband encourages me to use family planning $(B)$} \\
\hline & \multirow{2}{*}{\multicolumn{3}{|c|}{$\begin{array}{l}\text { OR } \quad 95 \% \text { CI } \\
\text { Model 1: Socio-demographic } \\
\text { variables }\end{array}$}} & \multirow{3}{*}{$\begin{array}{l}\text { OR } \\
\text { Model } \\
\text { (PCA) } \\
\text { contrace }\end{array}$} & \multirow{2}{*}{\multicolumn{2}{|c|}{$\begin{array}{l}95 \% \text { CI } \\
\text { 2: Add self-efficacy } \\
\text { scale \& perceived } \\
\text { eptive accessibility }\end{array}$}} & \multirow{2}{*}{\multicolumn{2}{|c|}{$\begin{array}{l}\text { OR } \quad 95 \% \text { CI } \\
\text { Model 1: } \\
\text { Socio-demographic } \\
\text { Variables } \\
\end{array}$}} & & \multirow{2}{*}{$\begin{array}{l}\text { OR } \\
\text { Model 2: } \\
\text { scale \& } \\
\text { accessibilit }\end{array}$} & \multicolumn{2}{|l|}{$95 \% \mathrm{CI}$} \\
\hline & & & & & & & & & & & $\begin{array}{l}\text { Add self-efficacy } \\
\text { perceived contrac } \\
\text { ty }\end{array}$ & $\begin{array}{l}\text { (PCA) } \\
\text { iceptive }\end{array}$ \\
\hline \multicolumn{12}{|c|}{ Thinks husband/partner approves of family planning } & \\
\hline No/don't know & - & Reference & & - & Reference & & - & - & & - & - & \\
\hline Yes & 1.85 & $1.40-2.44$ & $* * *$ & 1.58 & $1.18-2.12$ & $* * *$ & - & - & & - & - & \\
\hline \multicolumn{13}{|c|}{ Husband encourages her to use family planning } \\
\hline Strongly Disagree/Disagree & - & - & & - & - & & - & Reference & & - & Reference & \\
\hline Indifferent & - & - & & - & - & & 1.06 & $0.74-1.52$ & & 1.02 & $0.70-1.49$ & \\
\hline Agree/Strongly Agree & - & - & & - & - & & 1.22 & $0.88-1.68$ & & 0.97 & $0.68-1.38$ & \\
\hline \multicolumn{13}{|l|}{ Age } \\
\hline $15-19$ & - & Reference & & - & Reference & & - & Reference & & - & Reference & \\
\hline $20-24$ & 1.78 & $1.24-2.56$ & $* * *$ & 1.92 & $1.31-2.81$ & $* * *$ & 1.75 & $1.22-2.51$ & $* * *$ & 1.93 & $1.32-2.82$ & $* * *$ \\
\hline $25+$ & 1.27 & $0.84-1.91$ & & 1.26 & $0.82-1.94$ & & 1.23 & $0.82-1.84$ & & 1.24 & $0.81-1.90$ & \\
\hline \multicolumn{13}{|l|}{ Current Marital Status } \\
\hline Not married/cohabiting & - & Reference & & - & Reference & & - & Reference & & - & Reference & \\
\hline Married/cohabiting & 0.81 & $0.57-1.15$ & & 0.80 & $0.55-1.15$ & & 0.86 & $0.61-1.22$ & & 0.85 & $0.59-1.22$ & \\
\hline No education/grades 1-6 & - & Reference & & - & Reference & & - & Reference & & - & Reference & \\
\hline Grades 7-9 & 2.45 & $1.53-3.93$ & $* * *$ & 2.23 & $1.35-3.68$ & $* * *$ & 2.26 & $1.41-3.60$ & $* * *$ & 2.15 & $1.30-3.54$ & $* * *$ \\
\hline Grades 10-13/Univ. or more & 3.02 & $1.86-4.89$ & $* * *$ & 2.53 & $1.52-4.22$ & $* * *$ & 2.91 & $1.80-4.69$ & $* * *$ & 2.52 & $1.51-4.21$ & $* * *$ \\
\hline \multicolumn{13}{|l|}{ Wealth Quintile } \\
\hline 1st (poorest) & - & Reference & & - & Reference & & - & Reference & & - & Reference & \\
\hline $2^{\text {nd }}$ & 0.92 & $0.62-1.37$ & & 0.82 & $0.54-1.25$ & & 0.94 & $0.63-1.39$ & & 0.83 & $0.55-1.26$ & \\
\hline $3^{\text {rd }}$ & 1.24 & $0.82-1.86$ & & 1.12 & $0.73-1.73$ & & 1.30 & $0.87-1.94$ & & 1.16 & $0.75-1.78$ & \\
\hline
\end{tabular}


Prata et al

\begin{tabular}{|c|c|c|c|c|c|c|c|c|c|c|c|c|}
\hline $4^{\text {th }}$ & 1.13 & $0.75-1.70$ & & 0.97 & $0.62-1.50$ & & 1.17 & $0.78-1.77$ & & 0.99 & $0.64-1.53$ & \\
\hline 5th (wealthiest) & 1.45 & $0.95-2.23$ & $*$ & 1.18 & $0.75-1.84$ & & 1.52 & $0.99-2.31$ & $*$ & 1.21 & $0.78-1.90$ & \\
\hline \multicolumn{13}{|l|}{ Children Ever Born } \\
\hline 0 & - & Reference & & - & Reference & & - & Reference & & - & Reference & \\
\hline $1-2$ & 1.14 & $0.78-1.65$ & & 1.01 & $0.68-1.49$ & & 1.19 & $0.82-1.72$ & & 1.04 & $0.70-1.54$ & \\
\hline $5+$ & 2.43 & $1.31-4.53$ & $* * *$ & 2.51 & $1.30-4.83$ & $* * *$ & 2.41 & $1.30-4.46$ & $* * *$ & 2.54 & $1.32-4.89$ & $* * *$ \\
\hline \multicolumn{13}{|c|}{ Number of times have talked to husband/partner about family planning in the last year } \\
\hline Never & - & Reference & & - & Reference & & - & Reference & & - & Reference & \\
\hline Once or twice & 2.22 & $1.58-3.11$ & $* * *$ & 1.73 & $1.21-2.47$ & $* * *$ & 2.67 & $1.93-3.70$ & $* * *$ & 1.99 & $1.41-2.81$ & $* * *$ \\
\hline \multicolumn{13}{|c|}{ Perceives contraceptive as accessible } \\
\hline No & - & - & & - & Reference & & - & - & & - & Reference & \\
\hline Yes & - & - & & 3.27 & $2.46-4.35$ & $* * *$ & - & - & & 3.37 & $2.54-4.48$ & $* * *$ \\
\hline \multicolumn{13}{|c|}{ One unit increase in composite score on self-efficacy scale (1-5) } \\
\hline & & & & 2.03 & $1.56-2.63$ & $* * *$ & - & - & & 2.11 & $1.61-2.77$ & $* * *$ \\
\hline
\end{tabular}


Table 4: Self Efficacy Scale Items by Current Modern Method Use

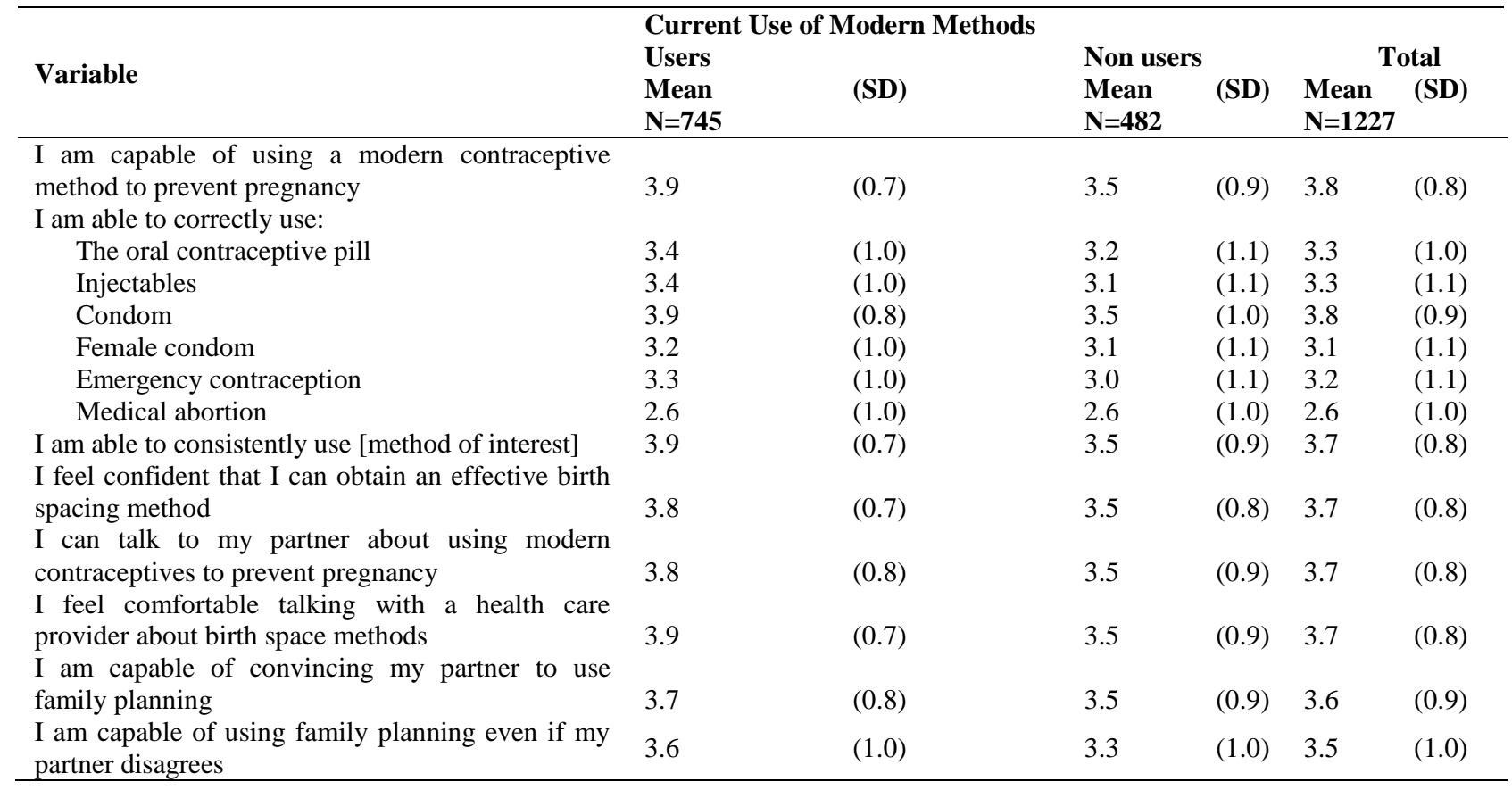

women who were aged 25 years or older are no longer significantly more likely to do so. Higher educational attainment (AOR=2.2-2.5, 95\% CI 1.4-4.2) and recent couple communication (AOR=1.7-1.9, 95\% CI 1.2-2.7) remained associated with currently using modern contraception. The number of CEB remained significantly associated with current modern method use for higher parity women $(\mathrm{CEB} \geq 3$ : $\mathrm{AOR}=1.6-2.5,95 \%$ CI 0.9-4.8). After controlling for mediators, women who had discussed family planning with their husbands in the last year were almost twice as likely (AOR=1.7-1.9, 95\% CI 1.22.7) to use of modern methods. A woman's perceived accessibility of contraception more than tripled her odds of using a modern method (AOR=3.3, 95\% CI 2.5-4.4) and for each unit increase in her self-efficacy score her odds of using modern contraceptive methods doubled (AOR=2.0, 95\% CI 1.6-2.6). Additional models, investigating potential interactions between partner's approval and each mediator, found the association between each interaction term nonsignificant (not shown).
In relation to husband's/partner's encouragement of family planning use (Table 3, Model 1), after controlling for sample characteristics, we found that although previously significant, the unadjusted association between husband's/partner's encouragement to use contraception and modern method use dropped below significance. Socio-demographic control variables show a similar pattern of association with the contraceptive use outcome in the husband's/partner's encouragement model as found in the husband's/partner's approval model. The odds of current modern contraceptive use associated with recent couple communication, although smaller, remained positive and significant in the adjusted model. In Model 1, women who had discussed family planning with their husbands more than once in the last year were 2.7-2.9 times as likely to currently use modern contraception (95\% CI 1.9-4.0). Model 2 presents the association between husband's/partner's encouragement and current modern method use, further adjusted for mediators. Both perceived accessibility and self- 
efficacy are significantly associated with modern use and controlling for these mediators improved the fit of the model. After adjusting for mediators, socio-demographic variables again show a similar pattern of association as found in the approval model. In contrast, while recent couple communication remains significant, the odds are higher in the encouragement model after the adjustments than in the corresponding approval model. Recent couple communication more than doubled the odds of current modern method use (AOR=2.0-2.3, 95\% CI 1.4-3.2).

\section{Discussion}

Our study examines the relationship between two aspects of gender dynamics and current modern contraceptive use independent of known factors and potential mediators. Results demonstrate that between these two forms of husband's/partner's support assessed in this study, perceived husband's/partner's approval, separate from a woman's sense of self-efficacy and the perceived accessibility of contraceptives, is the one variable strongly and positively associated with current modern contraceptive use. We also found the effect of perceived approval is further mediated by perceptions of accessibility of contraception and self-efficacy but found no evidence of interaction between approval and mediating factors. The association between husband's/partner's encouragement of family planning and current modern contraceptive use lost its significance when adjusted for sociodemographic variables and couple communication. We found mediating factors, perceived accessibility, and self-efficacy were significantly associated with encouragement and increased the explanatory power of the analysis. In investigating both forms of husband's/partner's support, several control variables, including most notably and unsurprisingly, couple communication were significant factors in the relationship between both husband's/partner's support variables and current modern methods use. Other research has pointed to the importance of spousal agreement on the desired family size, but our analysis found that concordance on ideal family size was not significant in multivariate analysis.

While our study relies on women's perception of their husband's/partner's approval, our results are consistent with other quantitative and qualitative studies which have found actual husband's/partner's approval wields significant influence on contraceptive use $\mathrm{e}^{10,14,22}$. Furthermore, women's perception of their husband's/partner's approval strongly influences their family planning behavior, so that unless approval is explicitly communicated, even incorrect perceptions of disapproval can pose a barrier to contraceptive use $^{7,23}$.

We found considerable ambiguity about husband/partner support for family planning and agreement on desired family size along with a substantial lack of recent couple communication. Just as some women might not adopt family planning due to incorrect perceptions of partner's approval, women who are unsure of their partner's opinions might decide not to use contraception (preemptively without discussion) due to fear of partner's opposition. In our analysis, we collapsed the category of women who did not know their partner's opinion about couples using family planning with women perceived their husbands/partners as disapproving of the practice. Our approach is consistent with a study of men's approval of family planning in Bangladesh, which validated collapsing disapproval and uncertainty into a single category based on the characteristics of indecisive respondents but also recommended further study ${ }^{24}$. Thus, the meaning of the "don't know" response might merit some further consideration. In our study most of the women in the "disapprove/don't know" fell under "don't know".

Poor communication likely fuels the uncertainty or indifference many women reported regarding perceived husband's/partner's approval or encouragement and concordance on ideal family size. Inter-spousal communication about family planning is often limited in many low-resource settings. Some researchers caution that frequent spousal communication should not be assumed to be associated with approval of contraceptive use ${ }^{25}$. 
Others research notes the lack of communication might not denote disapproval ${ }^{26}$. Qualitative research with Nigerian men found high male approval and ever use widespread but low current use and poor spousal communication regarding family planning ${ }^{27}$. Nevertheless, multiple studies suggest improving dialogue between couples in this regard may help women to more accurately identify husband's/partner's attitudes towards family planning ${ }^{8,28}$, and increase contraceptive use $^{29-31}$.

Overall, it is clear from this data from Angola that men's attitudes towards contraception, or at least women's perception of them, are predictive of women's contraceptive use. Male approval of family planning has been associated with increased male involvement ${ }^{32}$. Male involvement has been promoted in many quarters as a key to increasing contraceptive prevalence and has been called into question by others ${ }^{1,33-35}$.

Our study had some limitations. First, as mentioned, we relied on women's report of their husband's/partner's views. Matched couple data might be ideal but there are challenges to gathering data from dyads. Indeed, some research has found wives' perception of their husband's family planning attitudes might not reflect the husband's views ${ }^{36}$. Ultimately, as we have also noted, husband's actual approval might be interesting to know but, in some settings, it is possible that his wife's perception of his approval, accurate or not, might have more bearing on her family planning behavior ${ }^{3,7}$. Second, given differences seen in the results, there is a need to better understand what "approval" and "encouragement" really mean to women. For example, as with perceived approval, women's reports of husband's/partner's encouragement reflect subjective feelings, and likely are more nuanced and based on multiple overt actions or inaction. Husband's/partner's approval can be ascertained based on his disclosure of approval. However, encouragement would likely involve a pattern of behavior or actions, which might evolve throughout the relationship. In addition, approval of couples in general using contraception could be interpreted as philosophical or policy matter whereas husband's/partner's encouragement of his wife/partner (within a relationship) could be taken as interpersonal and situational. Partner encouragement may depend on many unknown factors including motivation, emotions, and relationship dynamics. For example, women may not respond to encouragement to limit fertility if she and her partner do not agree on family size or birth spacing. Moreover, in our study, the lack of association between concordance on desired fertility as perceived by the woman and modern method use found in our analysis contrasts with other studies which found a significant positive association for actual concordance from couple data $^{11}$. Additional qualitative work could be essential to understand this distinction and related nuances.

Nevertheless, our results have implications for future IEC campaigns designed to involve men in efforts to increase family planning use in Luanda, Angola. Existing largely qualitative research regarding men's actual attitudes points to some potential explanations. Several studies note the reasons men actually report for opposing contraception include concerns about side effects and potential promiscuity or infidelity ${ }^{32,37-39}$. It is possible that men who approve contraceptive use for couples in general but do not encourage their partners to use them ${ }^{26}$. Furthermore, some men participating in focus group discussions often report viewing family planning as a women's domain $^{39}$. Male involvement in family planning IEC could address misperceptions, myths, gender attitudes, and health concerns which make men more likely to oppose family planning and less likely to communicate their approval or voice encouragement, even if they approve.

Research suggests that the social networks and larger cultural context shape family planning norms and behaviors ${ }^{22,38,40-42}$. Husbands/partners are pivotal figures in the sexual and reproductive lives of women and contribute to the culture in which women live. With these influences in mind, family planning programs in Angola should consider targeting males in IEC campaigns to increase awareness and promote male involvement in helping to create a more supportive environment 
for women to adopt modern contraceptive methods.

\section{Acknowledgements}

Our secondary analysis drew on data gathered from the "Ouakula: Integrated Health Social Marketing Program", a United States Agency for International Development-funded program, implemented by PSI/Angola. Authors owe special thanks to Jorge Rivas, who as Research Director at PSI Angola, at the time of data collection, designed the study and to Elsa Caveya and Venceslau Pelenda, both PSI Angola Research Coordinators who supervised the field implementation. We are also grateful to Bixby Senior Intern, Emma Roos-Collins, for her assistance in analysis. This study reflects solely the perspectives of the authors and not necessarily the views of United States Agency for International Development.

\section{Contribution of Authors}

NP conceived of and designed the study; she also conducted data analysis and contributed to manuscript preparation; SB contributed to analysis and manuscript preparation; AF conducted analysis and drafted the manuscript; AC contributed to study design and data collection; IN contributed to study design and data collection; BNA contributed to study design, data collection and manuscript preparation. All authors approved the manuscript.

\section{References}

1. Ezeh AC. The influence of spouses over each other's contraceptive attitudes in Ghana. Stud Fam Plann 1993; 24(3):163-74.

2. Maharaj P and Cleland J. Women on top: The relative influence of wives and husbands on contraceptive use in KwaZulu-Natal. Women Health 2005; 41(2):31-41.

3. Yue K, O'Donnell C and Sparks PL. The effect of spousal communication on contraceptive use in Central Terai, Nepal. Patient Educ Couns 2010; 81 (3): 4028.

4. Koenig MA, Simmons GB and Misra B. Husband-wife inconsistencies in contraceptive use responses. Population Studies 1984; 38(2):281-98.
5. Kulczycki A. Husband-Wife Agreement, Power Relations And Contraceptive Use in Turkey. Int Fam Plan Perspec 2008; 34(3):127-37.

6. Becker S. Couples and Reproductive Health: A Review of Couple Studies. Studies in Family Planning 1996; 27(6):291-306.

7. Lasee A and Becker S. Husband-Wife Communication About Family Planning and Contraceptive Use in Kenya. Int Fam Plan Perspec 1997; 23(1):15-33.

8. DeRose LF, Dodoo FNA, Ezeh AC and Owuor TO. Does discussion of family planning improve knowledge of partner's attitude toward contraceptives? Int Fam Plan Perspec 2004; 30(2):87-93.

9. Yadav K, Singh B and Goswami K. Agreement and concordance regarding reproductive intentions and contraception between husbands and wives in rural Ballabgarh, India. Indian journal of community medicine: official publication of Indian Association of Preventive \& Social Medicine 2010; 35(1):19.

10. Esber A, Foraker RE, Hemed M and Norris A. Partner approval and intention to use contraception among Zanzibari women presenting for post-abortion care. Contraception 2014; 90(1):23-8.

11. Tilahun T, Coene G, Temmerman M and Degomme O. Spousal discordance on fertility preference and its effect on contraceptive practice among married couples in Jimma zone, Ethiopia. Reproductive Health 2014; 11.

12. Stephenson R and Tsui AO. Contextual influences on reproductive health service use in Uttar Pradesh, India. Studies in Family Planning 2002; 33(4):30920.

13. Williamson L, Parkes A, Wight D, Petticrew M and Hart G. Limits to modern contraceptive use among young women in developing countries: a systematic review of qualitative research. Reproductive Health 2009; 6(1):3.

14. Mubita-Ngoma $\mathrm{C}$ and Kadantu MC. Knowledge and use of modern family planning methods by rural women in Zambia. Curationis 2010; 33(1):17-22.

15. Advance Africa. Qualitative Factors Determining Poor Utilization of Family Planning Services in Angola: Results of the Strategic Mapping Exercise. USAID/Angola, 2003.

16. Decker M and Constantine NA. Factors associated with contraceptive use in Angola. African journal of reproductive health 2011; 15(4):68-77. Epub 2012/05/11.

17. INE. Resultados preliminares recenseamento geral da população e habitação - 2014. Luanda: Instituto Nacional de Estatística (INE), 2014.

18. USAID. Country Health Statistical Report, Angola, 2009. Washington, DC: United States Agency for International Development, 2009.

19. Connor C, Averbug D and Miralles M. Angola Health System Assessment 2010. Bethesda, MD, Health Systems 2010; 20:20.

20. Bell S, Weidert K, Vohra D, Harris L and Prata N. 
Community Survey Report, Cacuaco and Viana Municipalities, Luanda, Angola, 2012. Bixby Center for Population, Health and Sustainability, University of California, Berkeley, 2013.

21. Instituto Nacional de Estatistica (INE). Integrated Survey on the Welfare of Population, Volume 1. Lunada, Angola: INE, 2011.

22. Eliason S, Baiden F, Quansah-Asare G, Graham-Hayfron Y, Bonsu D, Phillips $\mathrm{J}$ and Awusabo-Asare K. Factors influencing the intention of women in rural Ghana to adopt postpartum family planning. Reproductive Health 2013; 10.

23. Bankole A and Singh S. Couples' fertility and contraceptive decision-making in developing countries: Hearing the man's voice. Int Fam Plan Perspec 1998; 24(1):15-24.

24. Islam MA, Padmadas SS and Smith PWF. Men's approval of family planning in Bangladesh. Journal of Biosocial Science 2006; 38(2):247-59.

25. Dodoo FNA, Ezeh AC and Owuor TO. Some evidence against the assumption that approval of family planning is associated with frequency of spouses' discussion of the subject. Population Studies-a Journal of Demography 2001; 55(2):195-8.

26. Berhane A, Biadgilign S, Amberbir A, Morankar S, Berhane A and Deribe K. Men's knowledge and spousal communication about modern family planning methods in Ethiopia. African journal of reproductive health $2011 ; 15(4): 24-32$.

27. Ijadunola MY, Abiona TC, Ijadunola KT, Afolabi OT, Esimai OA and OlaOlorun FM. Male involvement in family planning decision making in Ile-Ife, Osun State, Nigeria. African journal of reproductive health 2010; 14(4):45-52.

28. Araoye MO. Communication and decision-making about reproductive health issues within couples in Kwara State, Nigeria. Tropical Journal of Obstetrics and Gynaecology 2006; 23(1):63-9.

29. Shattuck D, Kerner B, Gilles K, Hartmann M, Ng'ombe T and Guest G. Encouraging Contraceptive Uptake by Motivating Men to Communicate About Family Planning: The Malawi Male Motivator Project. American Journal of Public Health 2011; 101(6):1089-95.

30. Ogunjuyigbe PO. Spousal communication, changes in partner attitude and contraceptive use among the Yorubas of Southwest Nigeria. J Soc Sci 2002; 6(1):59-64

31. Bawah AA. Spousal communication and family planning behavior in Navrongo: A longitudinal assessment. Studies in Family Planning 2002; 33(2):185-94.

32. Kassa M, Abajobir AA and Gedefaw M. Level of male involvement and associated factors in family planning services utilization among married men in Debremarkos town, Northwest Ethiopia. BMC International Health and Human Rights 2014; 14.

33. Sternberg P and Hubley J. Evaluating men's involvement as a strategy in sexual and reproductive health promotion. Health Promotion International 2004; 19(3):389-96.

34. Vouking MZ, Evina CD and Tadenfok CN. Male involvement in family planning decision making in sub-Saharan Africa - what the evidence suggests. Pan African Medical Journal 2014; 19:349-.

35. Hartmann M, Gilles K, Shattuck D, Kerner B and Guest G. Changes in Couples' Communication as a Result of a Male-Involvement Family Planning Intervention. Journal of Health Communication 2012; 17(7):802- 19.

36. Diro CW and Afework MF. Agreement and concordance between married couples regarding family planning utilization and fertility intention in Dukem, Ethiopia. BMC Public Health 2013; 13.

37. Odu OO, Ijadunola KT, Komolafe JO and Adebimpe WT. Men's knowledge of and attitude with respect to family planning in a suburban Nigerian community. Nigerian journal of medicine : journal of the National Association of Resident Doctors of Nigeria 2006; 15(3):260-5.

38. Ochako R, Mbondo M, Aloo S, Kaimenyi S, Thompson $\mathrm{R}$, Temmerman $\mathrm{M}$ and Kays $\mathrm{M}$. Barriers to modern contraceptive methods uptake among young women in Kenya: a qualitative study. BMC Public Health 2015; 15:118-

39. Kabagenyi A, Jennings L, Reid A, Nalwadda G, Ntozi J and Atuyambe L. Barriers to male involvement in contraceptive uptake and reproductive health services: a qualitative study of men and women's perceptions in two rural districts in Uganda. Reproductive Health 2014; 11.

40. Dynes M, Stephenson R, Rubardt M and Bartel D. The influence of perceptions of community norms on current contraceptive use among men and women in Ethiopia and Kenya. Health \& Place 2012; 18(4):766-73.

41. Kaggwa EB, Diop N and Storey JD. The role of individual and community normative factors: A multilevel analysis of contraceptive use among women in union in Mali. Int Fam Plan Perspec 2008; 34(2):7988.

42. Avogo W and Agadjanian V. Men's social networks and contraception in Ghana. Journal of Biosocial Science 2008; 40(3):413-29. 